\title{
Higher efficiency of the cooling unit
}

\author{
Wojciech Cepiński ${ }^{1, *}$ \\ ${ }^{1}$ Wrocław University of Science and Technology, Faculty of Environmental Engineering, Department \\ of Air Conditioning, Heating, Gas Engineering and Air Protection, 4/6 Norwida st., 50-373 Wrocław, \\ Poland
}

\begin{abstract}
The paper describes the issue of the combined work of the cooling unit with the air direct-contact, gravel, ground heat exchanger (Polish acronym BGWCiM), patented for the Wroclaw University of Science and Technology. The options of the combined work have been discussed; the document also presents schemes and proposes the algorithms of work. The cost-efficiency of the energy harvesting from the ground by the means of the proposed solution have been analyzed and compared for two work modes, with and without the BGWCiM. Moreover, the research results and experimental measurements were presented and discussed.
\end{abstract}

\section{Introduction}

In a world where there is a lack of sources for energy, along with the major usage of traditional fossil fuels, it is imperative to find better solutions to use more natural energy, while replenishing the resources that are used.

When planning, designing, and innovating projects, it is important to remember the following: legal requirements, the growing knowledge and trend of saving and renewing energy, along with the positive or negative impact it will cause, regardless of how significant.

It is worth noting that out of all the energy produced in Mid-European climate conditions, $40 \%$ is used for heating and cooling buildings.

\subsection{Air direct-contact, gravel, ground heat exchanger}

For more than 30 years, the Wroclaw University of Science and Technology has studied the effectiveness of extraction of cheap, natural, renewable energy from a small depth of the soil, in the air direct-contact, gravel, ground heat exchanger (Polish acronym BGWCiM) for the purposes of ventilation and air-conditioning [1]

*Corresponding author: wojciech.cepinski@pwr.edu.pl 


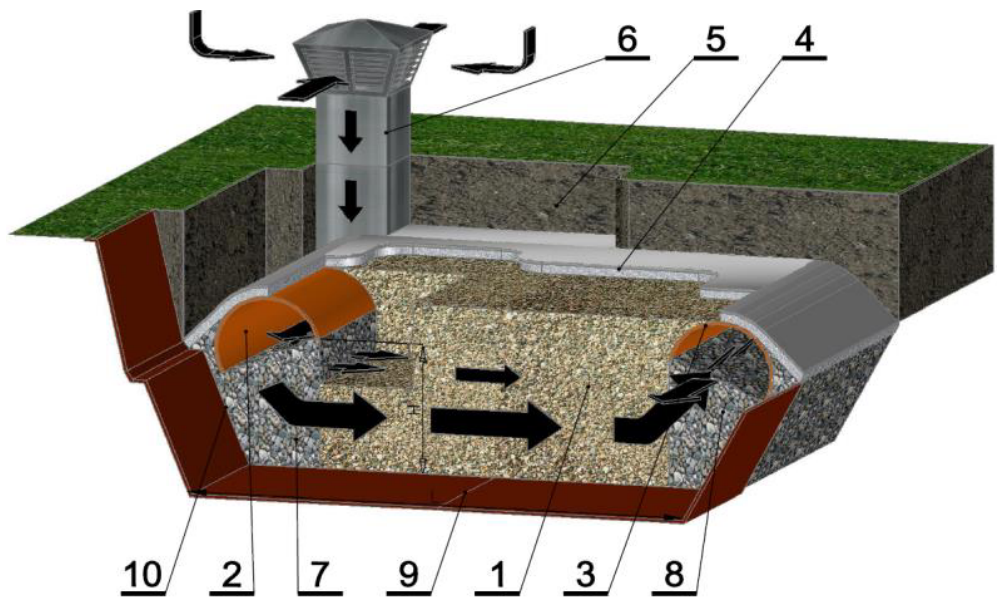

Fig.1. The air direct-contact, gravel, ground heat exchanger (Polish acronym BGWCiM) 1 - accumulating bed, 2 - conducting channel, 3 - collecting channel, 4 - heat- moisture insulation, 5 - covering blanket, 6 - draving air inlet, 7 - air distribution bed, 8 - air collecting bed, 9 - ground, 10 - geotextile $[1,4]$.

In the Mid-European climate, the ground temperature at $4-5 \mathrm{~m}$ deep is almost static throughout the year and is close to the average outdoor temperature (around $+10( \pm 1,5){ }^{\circ} \mathrm{C}$ ). A device to heat in the winter and cool in the summer can be constructed by placing the heat exchanging gravel bed of appropriate volume at a smaller depth or even at a ground surface level. This is how the BGWCiM works - shown in Figure 1. It was built and patented in the 1980's by prof. Gerard Besler at the Wroclaw University of Science and Technology, and has been used in Poland and overseas. The construction is very simple and inexpensive to build.

The exchanger can be installed in practically any place of the property (Fig. 2).

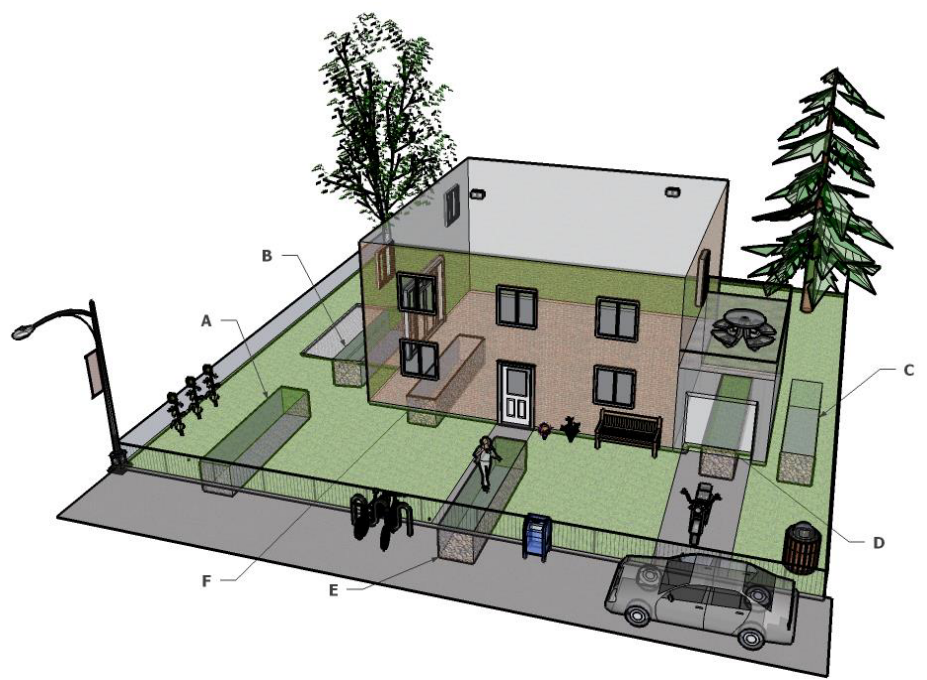

Fig. 2. Possible locations of the exchanger: $\mathrm{A}$ - in the lawn, $\mathrm{B}$ - below the terrace, $\mathrm{C}$ - along fences, $\mathrm{D}$ - below the garage, $\mathrm{E}$ - below the sidewalk, $\mathrm{F}$ - under the building [3].

In the exchanger, the outside air is supplied horizontally through a gravel bed length of 3-5 $\mathrm{m}$ (fig. 1) When the air flows between the gravel, the air temperature reaches the temperature of the gravel. Because of this, the temperature increases from $-18^{\circ} \mathrm{C}$ 
to around $0^{\circ} \mathrm{C}$ in the winter, and decreases from $+30^{\circ} \mathrm{C}$ to around $+20^{\circ} \mathrm{C}$ in the summer. The air pressure drop is relatively small, only 100 to $250 \mathrm{~Pa}$.

Figure 3 presents the average air temperature after passing through the BGWCiM, as well as the average outdoor temperatures in Wroclaw. The numbers are derived from many years of statistical measurements.

This figure can be used in the designing process, and serve as a reference to analyze the device's performance for the entire year.

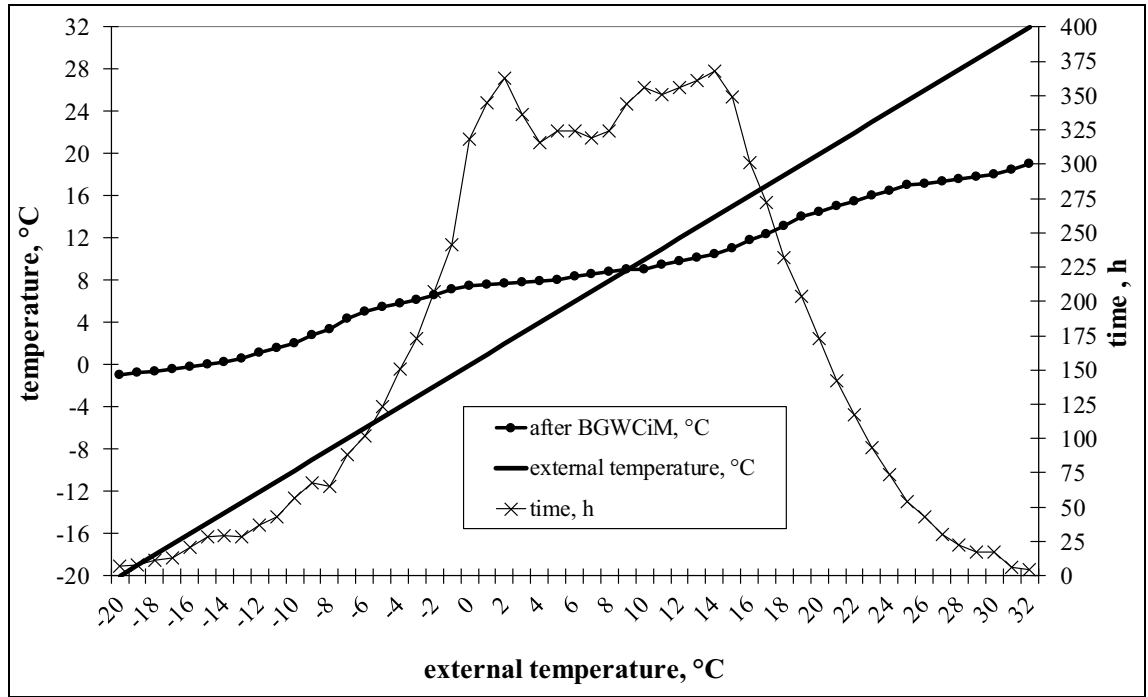

Fig. 3. Mean values of air temperature after the ground heat exchanger and occurrence time of given outdoor temperatures during the year $[2,4]$.

The exchanger's efficiency decreases during cold and warm periods. This is due to the changing temperature of the ground through outdoor temperature function.

This should be taken into account during the calculation, design, and installation of the BGWCiM.

\subsection{Cooling units}

Currently, the most popular air conditioning and cooling device that is used in Poland and overseas is the compressor unit with a condenser that is directly or indirectly cooled with atmospheric air. The condenser may be cooled directly by outside air or by water prepared in a wet cooling tower or in a dry cooler.

\section{Solution idea}

The original idea was to conjoin the compressor unit with the air direct-contact, gravel, and ground heat exchanger to increase the effectiveness of cooling energy production. Diagram of such a solution is shown in Figure 4. 


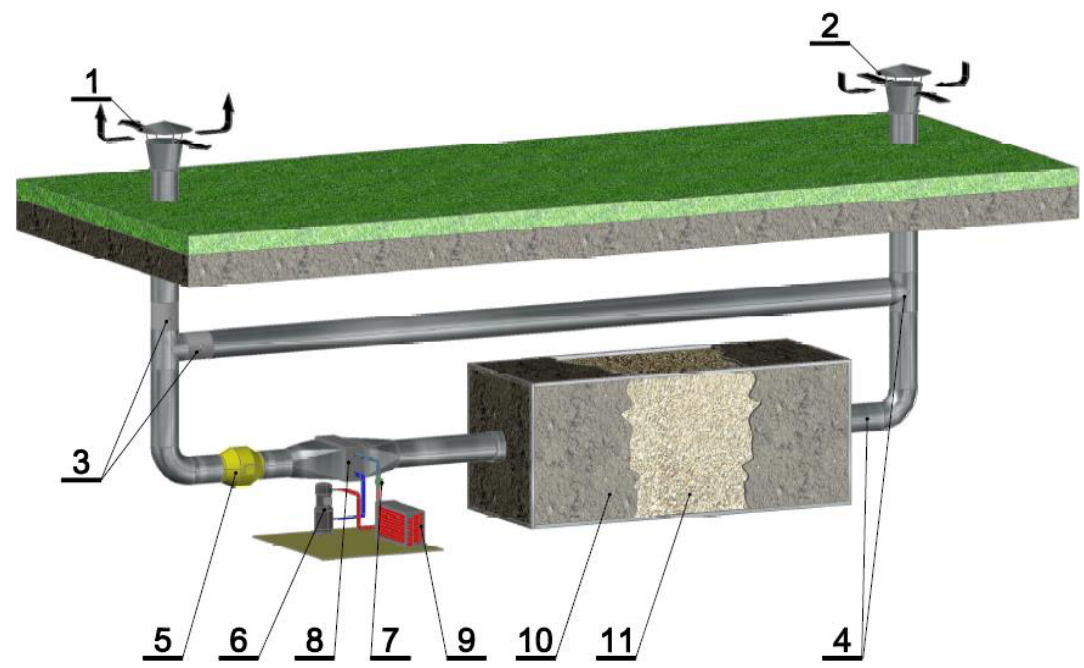

Fig. 4. Schematic diagram of the cooling unit with BGWCiM working in combination with each other, 1 - exhaust air, 2 - supply air, 3 - air damper, 4 - air ducts, 5 - fan, 6 - compressor, 7 - expansion valve, 8 - condenser, 9 - evaporator, 10 - heat exchanger, 11 - accumulating bed [3].

As a result of this, fluctuations of air temperature entering the condenser, both in the daily and seasonal cycle are considerably smaller, and improve the operating conditions and efficiency of the device. Due to the reduction of extreme parameters of the operation, it significantly increases the service life and reliability of the unit.

\section{Analysis}

The purpose of showing the collaboration between the cooling unit and BGWCiM is to show the fundamental benefits and risks.

The analysis was made for a single-family building located in Wroclaw. The cooling load of the building is $8,5 \mathrm{~kW}$.

During the warm period, the average external temperature was used to study and compare how the cooling unit performed with the BGWCiM, and how the same cooling unit worked with only external air.

The sum of internal heat gains, heat conduction, ventilation and maximum solar radiation for each outdoor temperature caused a demand for cooling energy.

\subsection{Power of the cooling unit}

Figure 5 presents the cooling capacity as the function of external temperature for operation with and without BGWCiM. Also, it shows the cooling demand of the building as a function of external temperature. When the cooling unit is linked with the BGWCiM, the cooling capacity increases substantially. It is noticeable during the entire warm period and even grows up to $20 \%$ during the hottest period. The cooperation of the cooling unit with BGWCiM enables to choose a smaller and cheaper unit. 


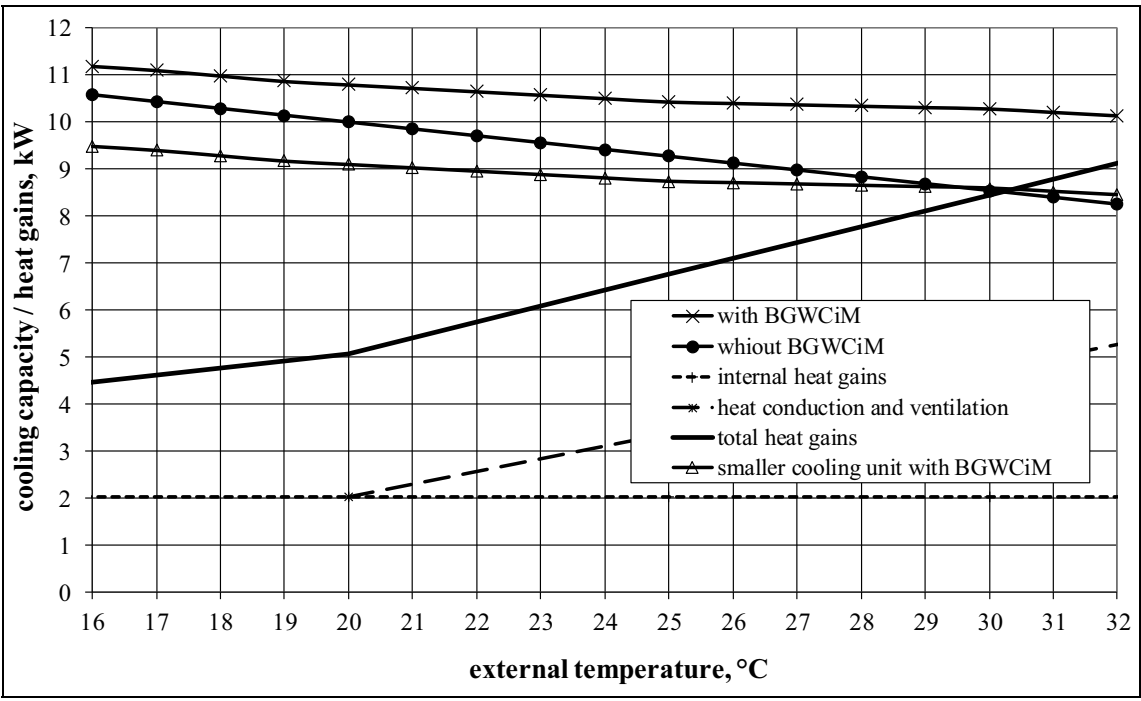

Fig. 5. Cooling capacity as the function of outdoor temperature.

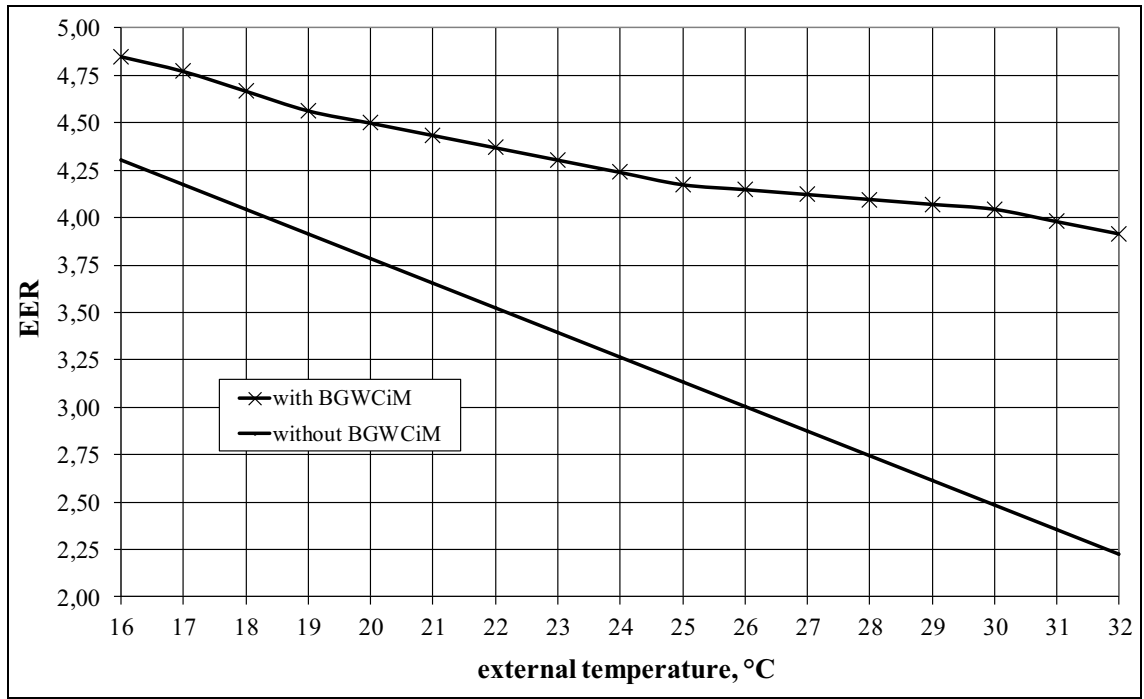

Fig. 6. EER coefficient as the function of outdoor temperature.

\subsection{Energy Efficiency Ratio EER}

The cooling unit's efficiency is defined by the energy efficiency ratio (EER). The EER is the ratio of the cooling capacity to the power input. The value of this coefficient depends mainly on the required temperature of the installation and the temperature of the source of energy, more specifically from the difference of these temperatures [5].

Increasing the energy efficiency ratio of the cooling unit in cooperation with BGWCiM in relation to the operation using the external air is significant for all operating temperatures. In the warmest moments EER is almost doubled and then cooling needs are highest. Figure 6 presents the EER coefficient as the function of external temperature. 


\section{Experimental data}

The measurements were performed in the laboraory located in Wrockaw. The graphs below present some examples of the experimental results obtained within the 2-year period of exploitation.

Figure 7 and 8 display exemplary results of the measurements from two different temperature phases during a summer period - the first and second half of the summer. These periods were characterized by typical summer temperature variabilities of atmospheric air over several days.

The graphs show that temperature variation is the result of cyclical operation.

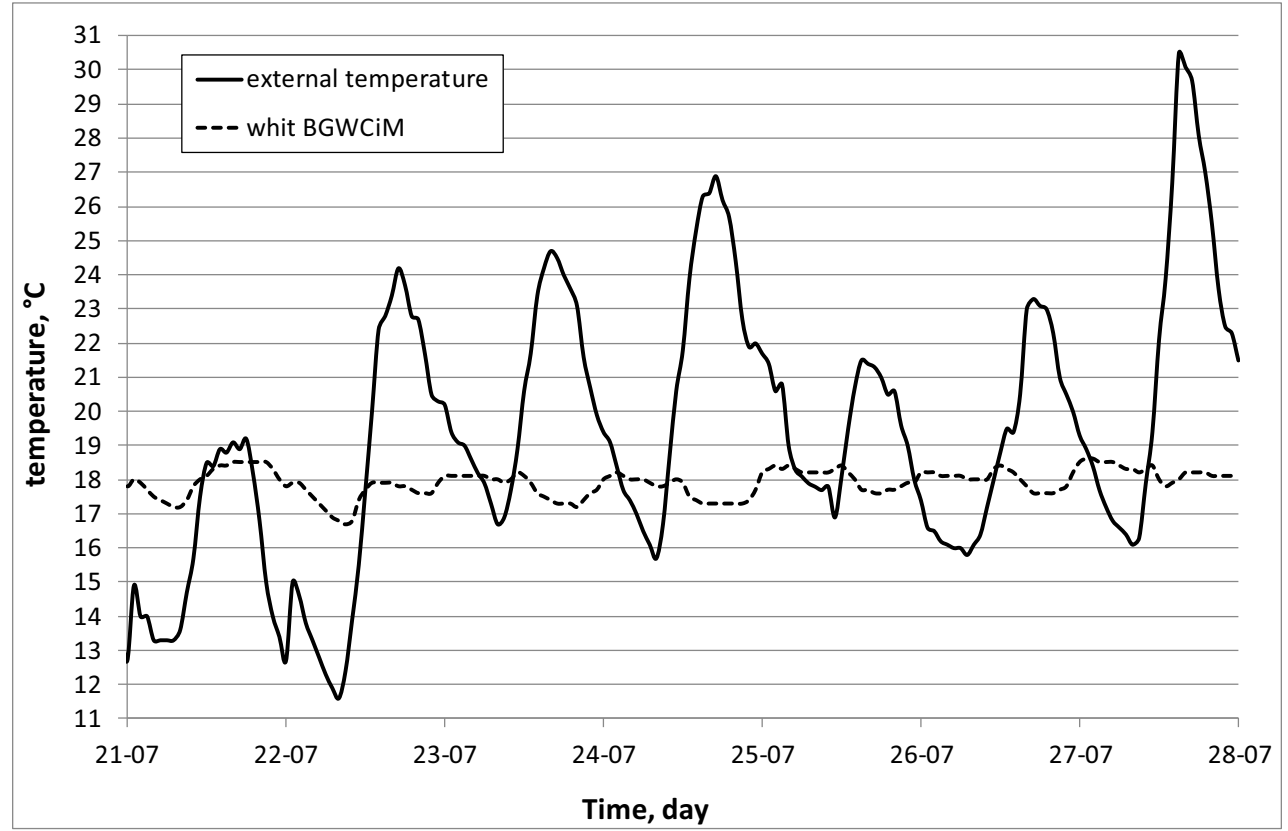

Fig. 7. Cooperation cooling unit with BGWCiM - selected week in July [4].

Research shows that the temperature of the air leaving the heat exchanger when working with a cooling unit, change in the manner established at the stage of theoretical considerations. It is characterized by small amplitude changes over a single day and multiday period. The lower temperature of the air leaving the heat exchanger in the first half of the study $\left(16^{\circ} \mathrm{C}-17^{\circ} \mathrm{C}\right)$ relative to the temperature of the second half $\left(18^{\circ} \mathrm{C}-20^{\circ} \mathrm{C}\right)$ is the result of accumulated cooling, which is a consequence of the cooling soil in the winter period and a slow discharge with the progress of the time. 


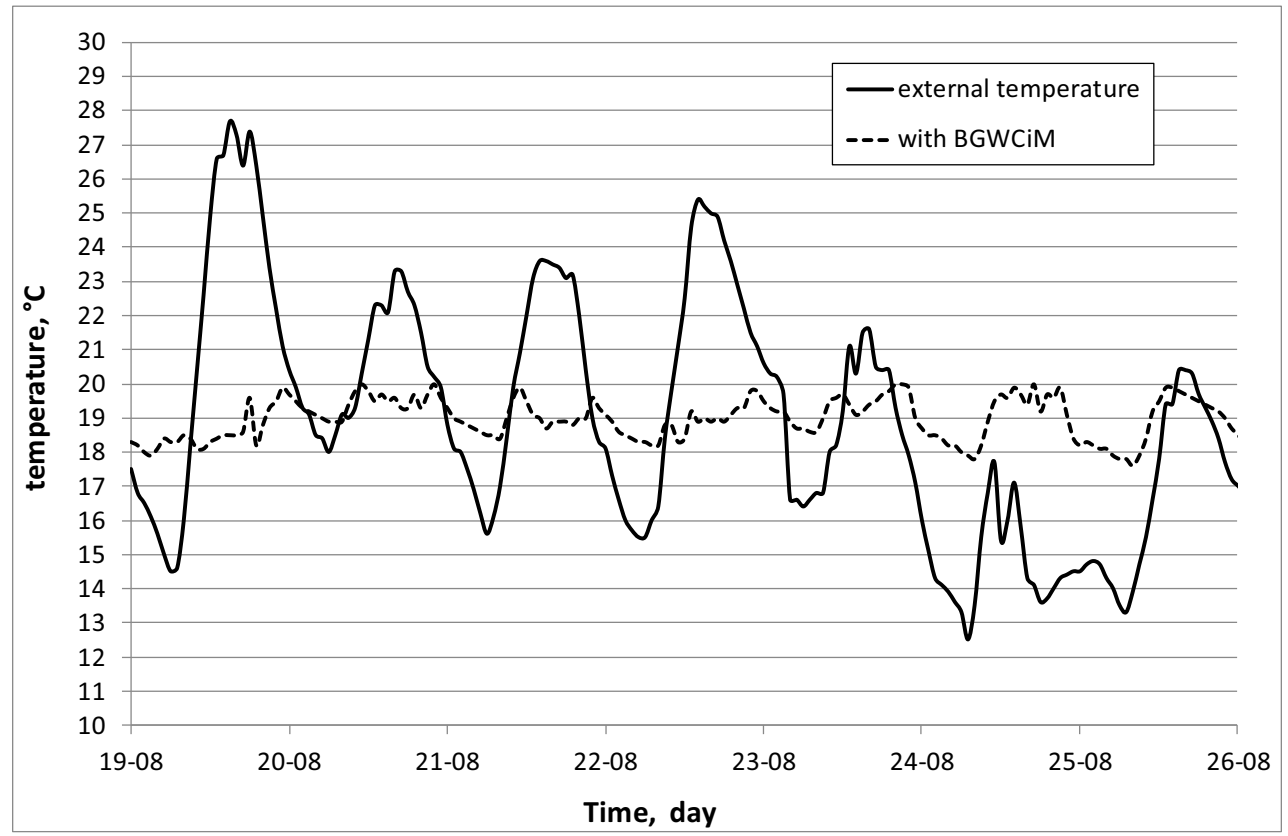

Fig. 8 Cooperation cooling unit with BGWCiM - selected week in August [4].

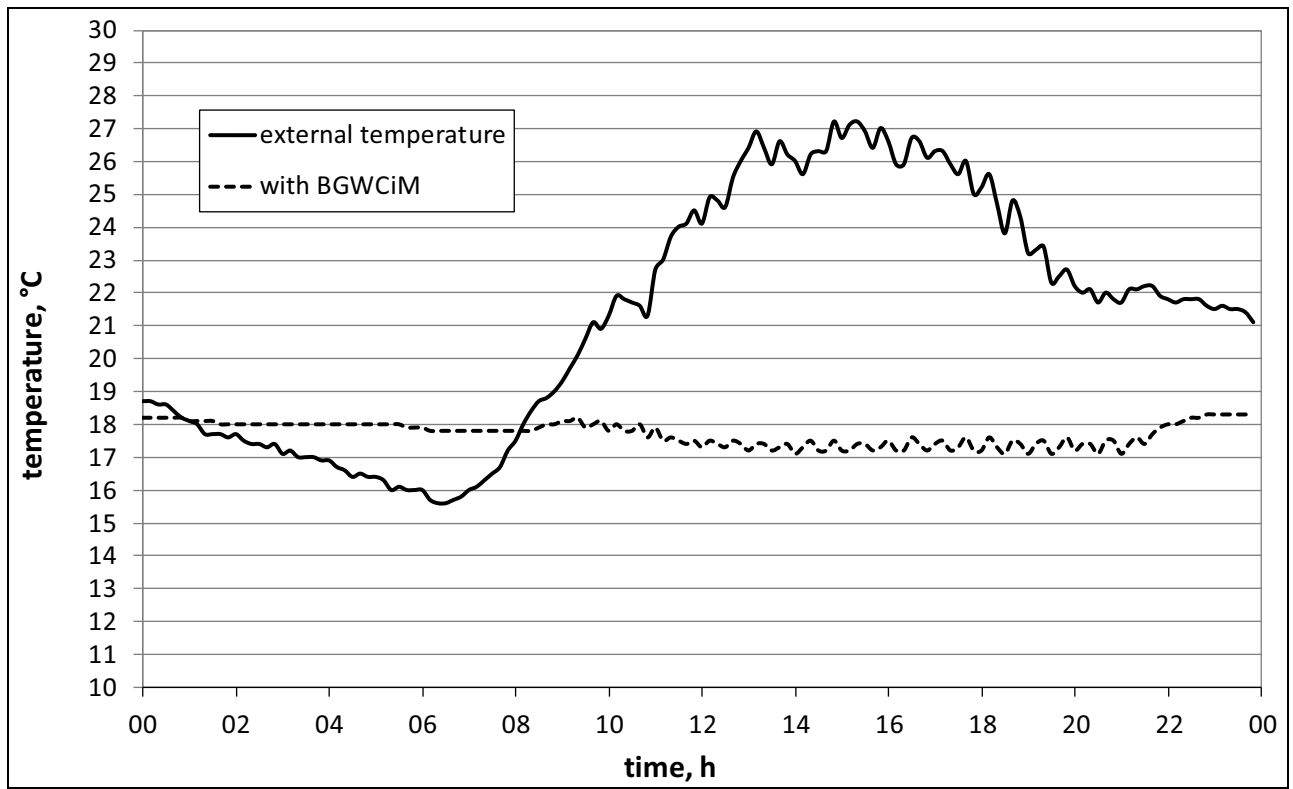

Fig. 9. Operation of the system in a typical summer day [4].

Figure 9 shows the operation of the system on a typical summer day. After a night's stopover, due to a lack of cooling demand during this period, and nightly bed regeneration at 9:30 due to the increase of temperature in the room which is the result of the growth heat gains, the cooling unit starts to work. As we can see, a system using the cooling unit ensures the necessary parameters of the microclimate in the room and lowers the the duration of time it needs to be used in a day. 
Over the analyzed summer period, during the use of the cooling unit operation:

- Air temperature after passing through the BGWCiM, flowing to the condenser over a single day has practically not changed, and in the perspective of the several days was associated with fluctuations in external conditions and ground load,

- Air temperature after passing through the BGWCiM changed in the range from $15^{\circ} \mathrm{C}$ to $20^{\circ} \mathrm{C}$, did not rise above $20^{\circ} \mathrm{C}$, and was lower than the outside air temperature $80 \%$ of the time.

\section{Conclusions}

Performed analysis and received results shows that using the BGWCiM together with the cooling unit can reduced the use of energy by $10 \%$ during the warm period.

When the cooling unit is conjoined with the BGWCiM it:

- causes much more favorable working condition devices, which results in smaller loads of components due to the reduction of temperature fluctuations.

- cuts off energy peaks which creates a lower failure rate, longer service life, durability and reliability

- increases the cooling capacity and give the possibility of buying a smaller cooling unit

- increases the average energy efficiency ratio

- shortens work time and reduces consumption of electric energy while maintaining the same conditions of the microclimate

BGWCiM conjoined with the cooling unit has many benefits. It produces renewable energy, is environment-friendly, and uses less electric energy.

\section{References}

1. G.J. Besler i inni, Bezprzeponowy gruntowy wymiennik ciepła i masy, Patent No. 128261 PRL Wroclaw University of Science and Technology Wrocław (1980)

2. M. Besler, Badania efektywności wykorzystania energii gruntu w inżynierii środowiska, PhD thesis, Wrocław (1997)

3. W. Cepiński, Efektywność pozyskiwania energii naturalnej. $\mathrm{PhD}$ thesis, Wrocław (2010)

4. S. Przydrożny, Wentylacja, Wydawnictwo Politechniki Wrocławskiej, Wrocław (1991)

5. M. Rubik, Pompy ciepła Poradnik, Ośrodek Informacji, Technika instalacyjna w budownictwie, Warszawa (2006) 